\title{
Dual AC-Drive System With a Reduced Switch Count
}

\author{
Enrique Ledezma, Brendan McGrath, Alfredo Muñoz, Member, IEEE, and Thomas A. Lipo, Fellow, IEEE
}

\begin{abstract}
A dual current-regulated pulsewidth-modulated voltage-source inverter based on multiple two-phase PWM inverters, also called a $\mathbf{B} 4$ topology, requiring a dual ac-drive system with reduced switch count is proposed. The drive utilizes a total of only eight switches to produce two sets of three-phase or two-phase sinusoidal output currents that can be employed to feed three-phase or two-phase induction motors. A suitable control strategy of this new scheme is shown to minimize the single-phase current flow through the dc-link capacitors, which is a common problem in reduced-switch-count topologies. In order to verify the performance of the motor drive system, an application on traction of an electric vehicle is carried out. Results show that the ac current through the de link can be minimized, and when utilizing two-phase motors on the proposed dual drive, the reduced voltage gain problem, also common in B4 topologies feeding three-phase motors, can be solved.
\end{abstract}

Index Terms-AC drives, inverters, multiple drive units, reduced-switch converters.

\section{INTRODUCTION}

D UE TO THE advances in power electronic technology, variable-frequency ac drives are presently being broadly applied. Traditional ac drives are based on a three-phase inverter that is used to feed an induction motor; thus, a total of six switches is required. Reducing the number of active switches is desirable in applications where low cost, improved reliability, and less conduction loss are of importance. Due to its many advantages, a number of studies have been conducted utilizing a reduced-switch-count structure. For instance, a two-phase topology using a split dc-link capacitor requiring only four switches was introduced in [1]. In [2], the same inverter, termed a B4 inverter, was proposed as a viable alternative compared to the conventional six-switch converter. A detailed analysis of the harmonic losses and torque pulsations produced by a four-switch voltage-controlled topology was carried out by Van Der Broeck et al. [2], [3]. This analysis showed that both copper losses and torque pulsations could be greatly reduced

Paper IPCSD 00-071, presented at the 1998 Industry Applications Society Annual Meeting, St. Louis, MO, October 12-16, and approved for publication in the IEEE TRANSACTIONS ON INDUSTRY APPLICATIONS by the Industrial Drives Committee of the IEEE Industry Applications Society. Manuscript submitted for review October 15, 1998 and released for publication June 5, 2001.

E. Ledezma was with the Department of Electrical and Computer Engineering, University of Wisconsin, Madison, WI 53706-1691 USA.

B. McGrath is with the Department of Electrical and Computer Systems Engineering, Monash University, Clayton, 3168 Australia (e-mail: brendan.mcgrath@eng.monash.edu.au).

A. Muñoz was with the Department of Electrical and Computer Engineering, University of Wisconsin, Madison, WI 53706-1691 USA. He is now at Balmaceda 263, Renaca, Vina del Mar, Valparaiso, Chile.

T. A. Lipo is with the Department of Electrical and Computer Engineering, University of Wisconsin, Madison, WI 53706-1691 USA (e-mail lipo@engr.wisc.edu).

Publisher Item Identifier S 0093-9994(01)08317-7. by instantaneously controlling the time shift between the two voltage pulses during the pulse period.

A three-phase-to-three-phase voltage-source inverter-pulsewidth-modulated (VSI-PWM) rectifier-inverter scheme with eight switches was proposed in [4]. This topology had the capability of delivering sinusoidal input currents with unity power factor and bidirectional power flow. The problem of voltage fluctuation in the dc link, however, is a potential limitation for this eight-switch structure. Drawbacks of the reduced-switch topologies also include increased voltage stress on both the power devices and the induction motor, increased switching losses due to a higher dc-link voltage, and single-phase circulating currents through the dc-link capacitors [5]. The problem of single-phase circulating currents through the dc-link capacitors was also addressed in [6]. A comparative study of a reduced-switch drive structure was conducted and applied to mobile robot motorization in [7]. However, the problem of the single-phase currents was not addressed, which is a common limitation of reduced-switch count topologies. In addition, the existence of large dc-link voltage variations due to, among other causes, the circulation of single-phase currents through the dc-link capacitors was discussed in [8], although a solution was not given.

This paper introduces a new dual ac-drive system that minimizes the single-phase current flow through the dc-link capacitors, thus eliminating their voltage variation and extra losses. The proposed drive system uses two four-switch inverters connected back to back which share a single split dc-link capacitor. The inverters are used to feed two induction motors that operate at the same fundamental frequency with a similar current level. It is shown that when a two-phase motor is used, the switch utilization ratio of each four-switch inverter is the same as the conventional six-switch inverter configuration. The benefits and constraints of utilizing three-phase induction motors are also addressed. To verify the performance of the dual drive system, an application on traction of an electric vehicle is carried out. A mathematical model of the proposed ac drive is derived and applied through simulation. An experimental work is currently being conducted. Details of the implementation and experimental results will be presented in a future paper.

\section{System Configuration AND PRINCIPLE OF OPERATION}

The proposed drive system is schematically shown in Fig. 1. The two-motor drive contains a dual two-phase inverter connected back to back with a common dc bus, thus requiring only eight switches instead of the conventional 12. In a two-phase inverter topology, two of the machine's lines are connected to two poles of the inverter, and the third line is connected to the center point of the dc link. It is assumed that a single bridge 


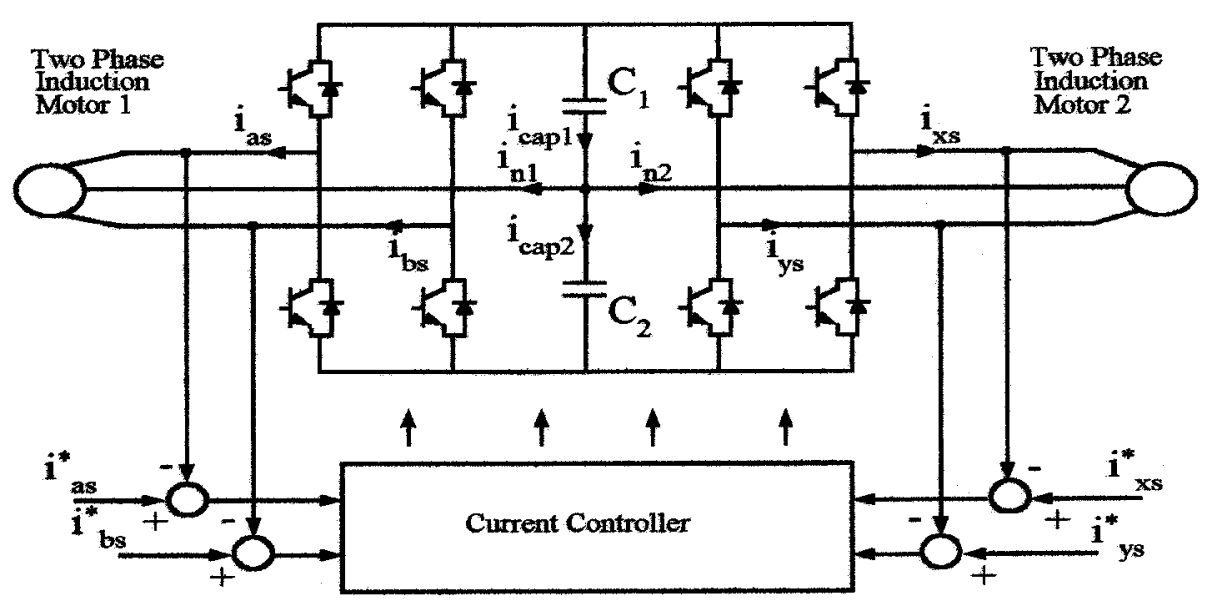

Fig. 1. Reduced-switch-count ac dual drive.

rectifier (not shown for simplicity) supplies the pole-to-pole dc-bus voltage. It is also assumed that the phase and magnitude of the load currents can be independently adjusted and that each inverter is operated under current control using hysteresis regulators. The load can be selected as either three-phase or two-phase induction machines that are fed from each inverter. If three-phase induction motors are utilized, assuming no neutral connection, only two of the three line currents need to be regulated (sinusoidal) since the current through the third line is the algebraic sum of the other two regulated currents. If the drive employs two-phase induction motors, the same current control as described above can be utilized. In this case, two line currents are regulated and are $90^{\circ}$ out of phase while the third line is the neutral connection and carries a current that is $\sqrt{ } 2 \times$ larger than the line current.

It is clear that this configuration creates a single-phase ac current flow through the capacitors. This result is due to the connection of one machine line to the center point of the dc link. However, by connecting a second two-phase inverter and motor to the same dc bus, as shown in Fig. 1, it is possible to compensate for the single-phase current in the capacitors. This is achieved by adjusting the relative phase angle of the currents in the two inverters. To eliminate the single-phase current, the relative line currents in each inverter must simply be $180^{\circ}$ out of phase. To develop actively this control strategy, a complex space vector approach is utilized.

\section{CONTROL STRATEGy}

When a dual two-phase inverter feeds two-phase induction motors, the current through $C_{1}$ in Fig. 1 is given by

$$
i_{\text {cap1 }}=i_{n 1}+i_{n 2}+i_{\text {cap2 }}
$$

where $i_{n 1}$ and $i_{n 2}$ are the neutral currents and $i_{c a p 2}$ is the current through $C_{1}$. From (1), it can be noted that if $i_{n 1}$ has the negative value $-i_{n 2}$, then $i_{\text {cap1 }}$ will be equal to $i_{\text {cap2 }}$. Therefore, the currents into the capacitor midpoint tap will total to zero. As a consequence, the effective circulating current through the dc-link capacitors will be ideally zero.

In (1), to minimize the single-phase circulating current through the dc-link capacitors, the neutral currents $i_{n 1}$ and $i_{n 2}$

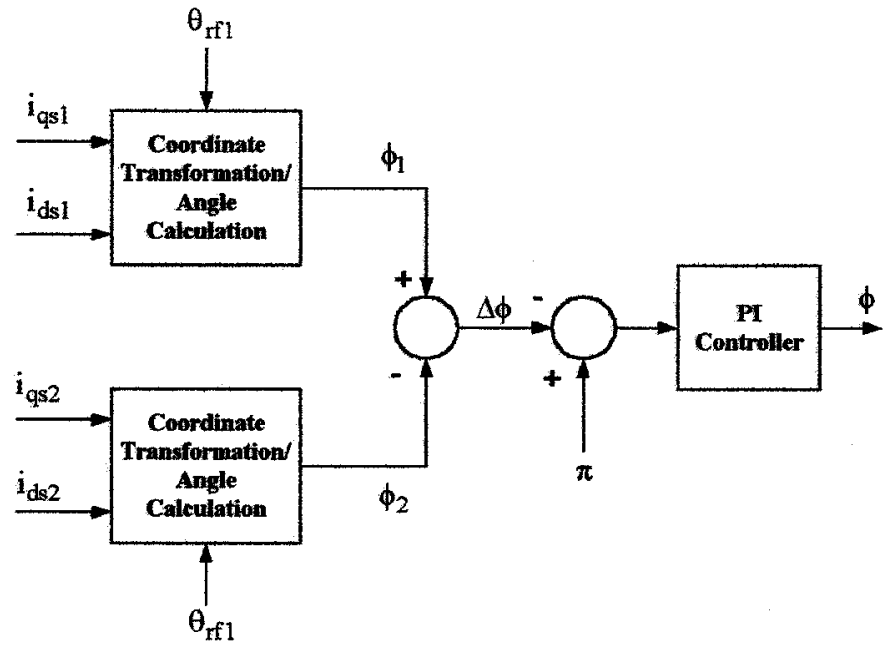

Fig. 2. Active calculation of the rotation angle $\phi$.

must be $180^{\circ}$ out of phase. This is accomplished by choosing the current references for inverter 1 , as follows:

$$
\begin{aligned}
& i_{a s}^{*}=i_{q 1}^{e *} \cos \theta_{r f 1}+i_{d 1}^{e *} \sin \theta_{r f 1} \\
& i_{b s}^{*}=i_{q 1}^{e *} \sin \theta_{r f 1}-i_{d 1}^{e *} \cos \theta_{r f 1}
\end{aligned}
$$

where $i_{q 1}^{e *}$ is the torque command, and $i_{d 1}^{e *}$ is the flux command in the synchronous reference frame. In the same fashion, the current references for inverter 2 are chosen as

$$
\begin{aligned}
& i_{x s}^{*}=i_{q 2 \mathrm{rot}} \cos \theta_{r f 2}+i_{d 2 \mathrm{rot}} \sin \theta_{r f 2} \\
& i_{y s}^{*}=i_{q 2 \mathrm{rot}} \sin \theta_{r f 2}-i_{d 2 \mathrm{rot}} \cos \theta_{r f 2} .
\end{aligned}
$$

In (4) and (5), $i_{q 2 \text { rot }}$ and $i_{d 2 \text { rot }}$ are chosen such that

$$
\begin{aligned}
& i_{q 2 \mathrm{rot}}=i_{q 2}^{e *} \cos \phi-i_{d 2}^{e *} \sin \phi \\
& i_{d 2 \mathrm{rot}}=i_{q 2}^{e *} \sin \phi+i_{d 2}^{e *} \cos \phi
\end{aligned}
$$

where $i_{q 2}^{e *}$ and $i_{d 2}^{e *}$ are the torque and flux commands for induction machine 2. In (6) and (7), the angle $\phi$ is determined as indicated in the block diagram of Fig. 2. Here, $i_{q s 1}, i_{d s 1}$, $i_{q s 2}$, and $i_{d s 2}$ are the inputs of measured stator currents in the stationary reference frame. The currents are transformed to the 


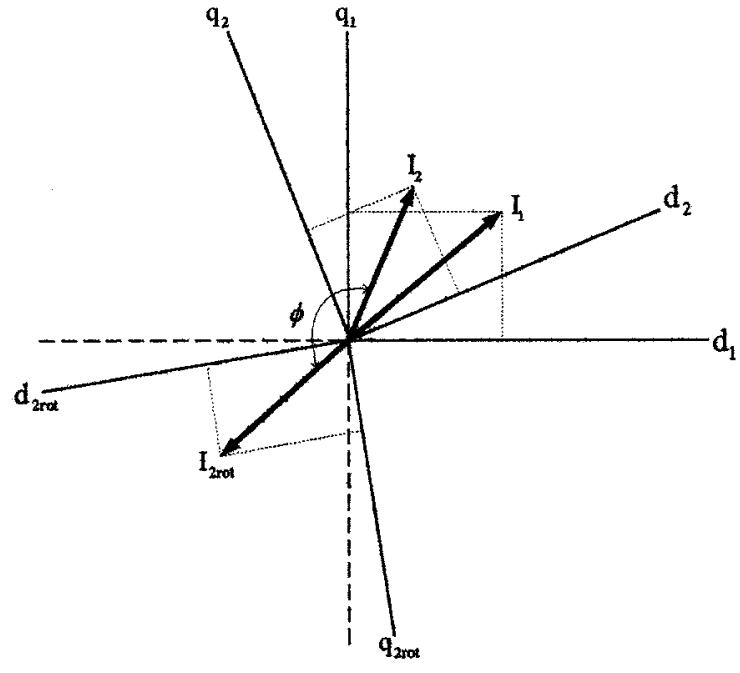

Fig. 3. Rotation of the reference frame of motor 2 by $\phi$ degrees with respect to the reference frame of motor 1 .

synchronous reference frame by utilizing the flux rotor position $\theta_{r f 1}$ in both transformations in order to have the currents referred to a common frame of reference.

After the transformations, new currents referred to the rotor flux frame of induction machine 1 are obtained. The positions of the complex current vector for induction machine $1, \phi_{1}$, and induction machine $2, \phi_{2}$, are calculated employing the current components. Angles $\phi_{1}$ and $\phi_{2}$ become

$$
\begin{aligned}
& \phi_{1}=a \tan \left(\frac{i_{q 1}^{e}}{i_{d 1}^{e}}\right) \\
& \phi_{2}=a \tan \left(\frac{i_{q 2}^{e}}{i_{d 2}^{e}}\right) .
\end{aligned}
$$

Fig. 2 shows the active calculation process for the rotation angle $\phi$. The error $\left(\phi_{1}-\phi_{2}\right)=\Delta \phi$ is calculated and compared to $\pi$ and further processed through a proportional-plus-integral (PI)-type controller. The actual angle $\phi$ is found as

$$
\phi=k_{p \phi}(\pi-\Delta \phi)+k_{i \phi} \int_{0}^{t}(\pi-\Delta \phi) d t .
$$

Angle $\phi$, when used in (6) and (7), has the property of rotating the complex current vector $I_{2}$ to be $180^{\circ}$ out of phase with respect to the complex current vector $I_{1}$. This rotation process is shown graphically in Fig. 3.

In this figure, the new position of the complex current vector of induction machine $2, I_{2 \text { rot }}$, is accomplished by rotating the complex vector $I_{2}$ by $\phi$ degrees. The reference frame of induction machine 1 remains fixed because the rotor flux angle $\theta_{\mathrm{rf} 1}$ was selected as the reference. In Fig. 3, there are three different reference systems: $q_{1} d_{1}$, which defines the position of induction machine $1, q_{2} d_{2}$, which defines the position of induction machine 2 , and $q_{2 \text { rot }} d_{2 \text { rot }}$, which defines the new position of machine 2. Thus, it can be noted that, in this new position, the complex current vectors $I_{1}$ and $I_{2}$ are $180^{\circ}$ out of phase. This is an important result because if $I_{1}$ and $I_{2}$ have similar magnitudes, which is possible during normal drive operation, the elimination of the single-phase current through the dc-link capacitors can be achieved according to (1). Once $\phi$ is calculated by
TABLE I

Switch Utilization Ratio AND Voltage Gain COMPARISON BETwEen SIX-SWITCH AND FOUR-SWITCH INVERTERS

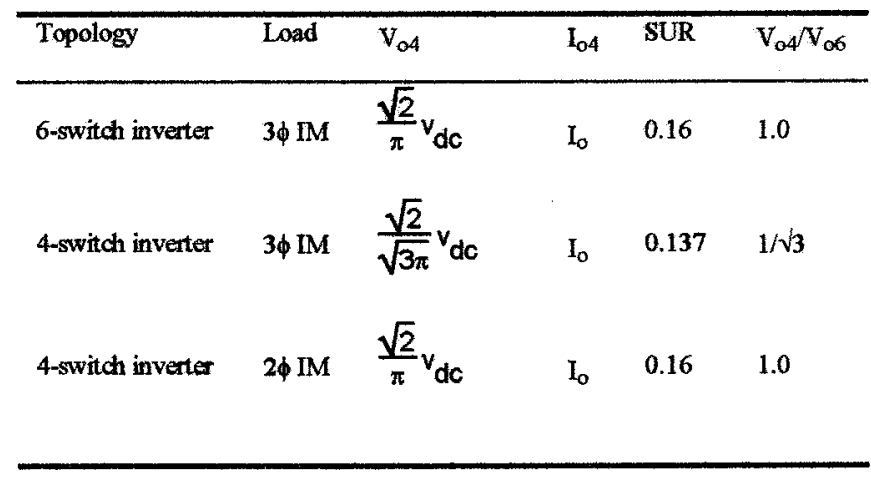

the PI-type controller in (10), it is utilized to generate the proper sets of reference currents in (4) and (5) for induction motor 2.

\section{DuAl DRIVE PERFORMANCE}

\section{A. Switch Utilization}

In order to compare the performance of this drive to that of the conventional six-switch converter, the switch utilization ratio (SUR) can be determined [11]. When the proposed dual ac drive employs two-phase induction motors, the SUR is calculated as

$$
\mathrm{SUR}=\frac{k v a_{\mathrm{out}}}{q V_{T} I_{T}}=\frac{2 V_{04} I_{04}}{q V_{T} I_{T}}=0.16
$$

where $V_{O 4}$ and $I_{O 4}$ are the rms inverter rated fundamental output voltage and current at fundamental frequency for a four-switch inverter. Similarly, $V_{T}$ and $I_{T}$ are the peak voltage and current ratings of a switch. Table I shows the SUR and the gain $V_{04} / V_{o 6}$, where $V_{o 6}$ is the fundamental phase voltage for the six-switch inverter case. In Table I, it is assumed that the dc-link voltage is fixed and each switch has the same ratings. It can be noted that the SUR and the fundamental phase voltage for the four-switch inverter with two-phase induction motors are equal to the corresponding values of the conventional six-switch inverter, whereas the rating is poorer for three-phase machines, as has been previously noted [2]. This means that the proposed dual four-switch inverter will exhibit the same range of voltage control and the same relative inverter losses as in the conventional six-switch inverter. Also, it is well known that a three-phase machine will exhibit higher output power density than a two-phase machine due to a better utilization of the core and windings. These two alternatives offer important benefits and constraints, which are being considered for the construction of a prototype.

\section{B. Induction Motor Drive Losses}

For low-speed drive applications, the major concern is the winding $I^{2} R$ losses since the core losses are relatively low. Therefore, it is interesting to observe the $I^{2} R$ losses in each motor as the ratio of their currents change. Fig. 4(a) shows the normalized $I^{2} R$ loss of motor 1 as its torque ratio $T=T_{1} / T_{2}$ and speed ratio $\omega_{1} / \omega_{2}$ are varied, provided that nominal conditions are sustained in the second machine. As the speed of induction motor 1 becomes lower than the speed of induction motor 2, the speed difference will drive up the losses in the motor drive. 


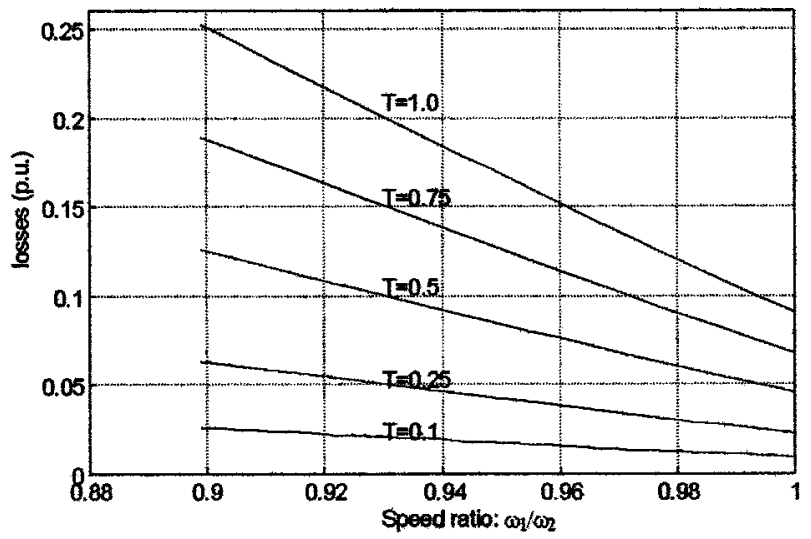

(a)

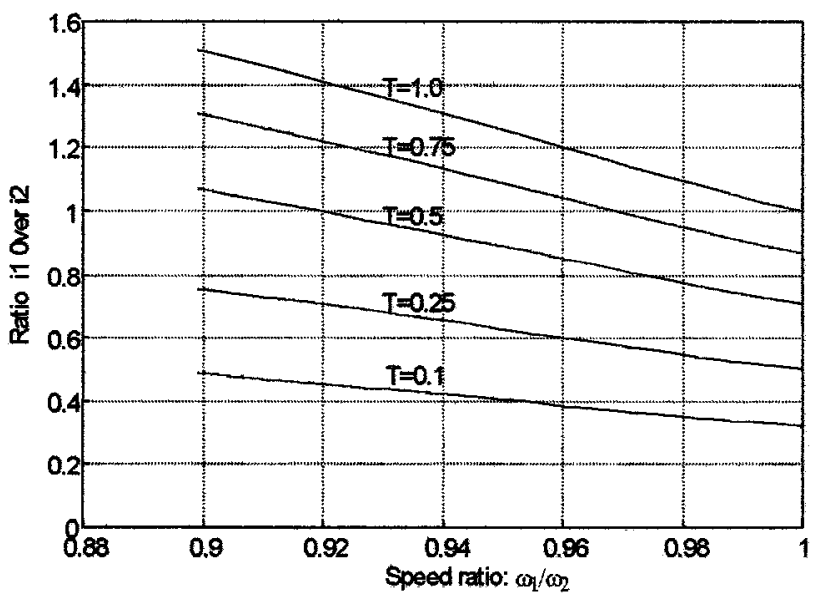

(b)

Fig. 4. Motor drive loss. (a) Induction motor $1 I^{2} R$ loss as a function of speed and torque. (b) Inverter output current ratio. In all cases, motor 2 is maintained at rated conditions.

As is observed in Fig. 4(a), the efficiency of the ac drive improves as both machines work near the same speed. At zero speed difference, the performance of this drive will exhibit constant losses similar to conventional dual six-switch converters.

Fig. 4(b) shows the output current ratio of inverter 1 over inverter 2 . As the speed and torque decrease, the current in machine 1 will tend to be equal to the current in motor 2 due to the increase of the losses. If the current ratio is maintained close to unity, the ac current component through the dc-link capacitors will still be considerably minimized. Fig. 4 suggests, however, that the dual motor drive must be operated within a safe speed difference range in order to avoid high $I^{2} R$ machine losses. Because both machines must operate at the same electrical frequency, regardless of the mechanical speed, there will be a limitation to the maximum mechanical speed difference. This limit is given by the breakdown slip in both machines. Due to the fact that the majority of high-performance traction drives briefly require no more than a $10 \%$ speed difference, the proposed motor drive will typically operate over a relatively safe range.

\section{Low-Speed Operation}

As long as an appropriate current control is maintained at low speed, the ac drive shown in Fig. 6 will exhibit a smooth

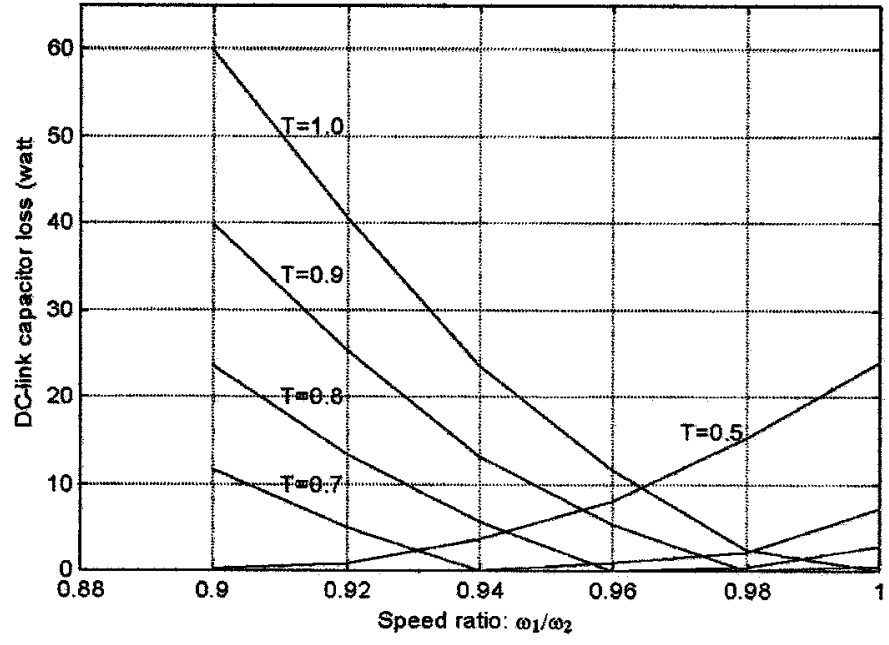

Fig. 5. DC-link capacitor loss as a function of machine speed ratio $\omega_{1} / \omega_{2}$ and load torque ratio $T=T_{1} / T_{2}$.

operation at zero speed. Due to the challenge of coordinating a multimachine drive system at a very low speed, an experimental work is being conducted to verify the present results in practical situations.

\section{DC-Link Capacitor Sizing}

Fig. 5 shows the dc-link capacitor losses as a function of the speed ratio $\omega_{1} / \omega_{2}$ and the load torque ratio $T=T_{1} / T_{2}$ of the proposed motor drive system. The bulkiness of the dc link will depend on the ability of the capacitors to absorb the ripple current, with a main spectral component at $60 \mathrm{~Hz}$, as the speed and torque ratios are varied. For instance, for a suitable design, the dc link can be sized to dissipate a maximum of $25 \mathrm{~W}$, as shown in Fig. 5. This defines an operating zone from 1.0 to 0.5 torque ratio and from 1.0 to 0.9 speed ratio. To limit the system operation in this zone, two $3400-\mu \mathrm{F}$ capacitors can be used. As a result, each of the two capacitors will have the ability to tolerate a maximum ripple current of $19 \%$ of the motor phase current, allowing a modest dc-link size. This can be compared to a bulky dc link needed to manage $70 \%-100 \%$ ac circulating current (ripple current) of a four-switch inverter [2] without any control.

\section{Traction Electric Vehicle ApPlication}

For an electric vehicle traction application, three driving situations are of interest: 1) the straight-line regime, where both motors operate at the same speed; 2) the turning regime, where each machine operates at different speeds; and 3) wheel slippage, where one of the induction motors experiences almost zero load torque. Fig. 5 illustrates the general block diagram for the controls of the proposed drive system.

\section{A. Velocity Commands}

In the block diagram of Fig. 6, it is assumed that the vehicle total velocity $(v)$ is maintained constant during each maneuver. The torque produced is developed by a throttle command. Each induction motor of the proposed drive is utilized to drive one of the wheels of the traction axle. The angular speed for each 


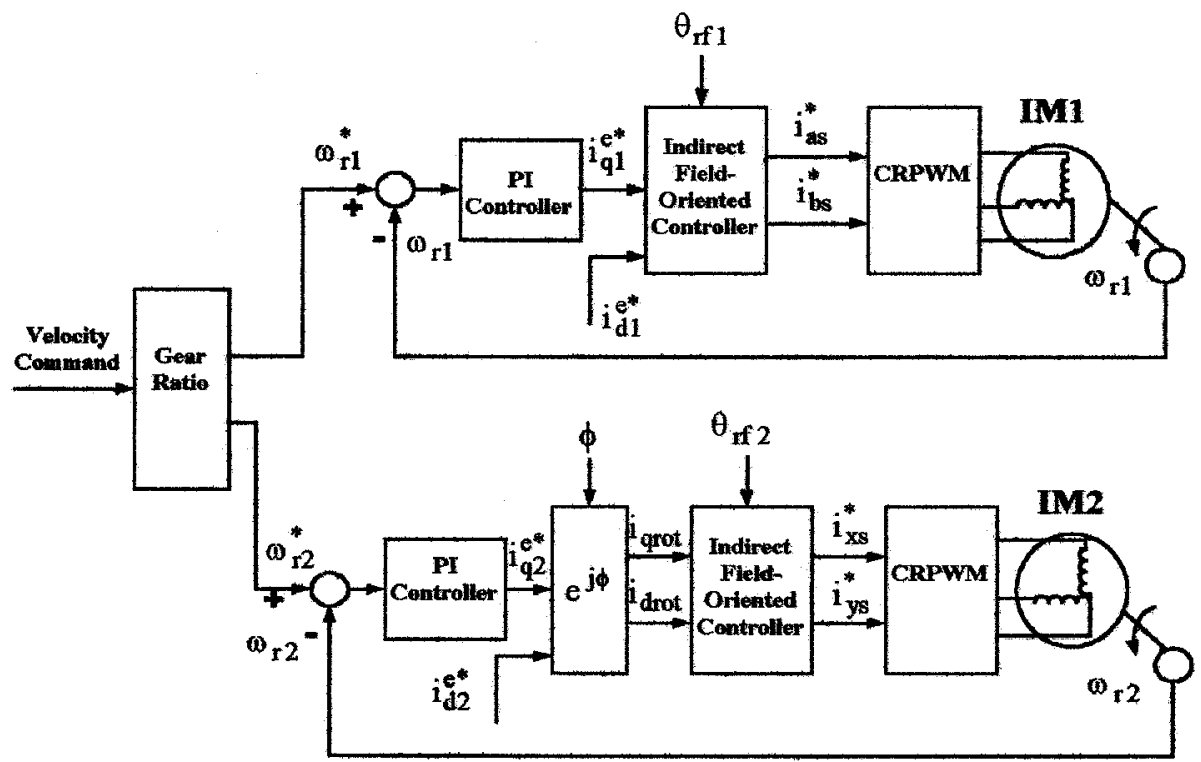

Fig. 6. General block diagram for the control of the proposed drive system using two-phase induction motors.

motor depends on the type of driving regime selected. For the straight-line regime, the angular speeds for each motor become

$$
\omega_{r 1}=\omega_{r 2}=\frac{v}{R_{w}} .
$$

For the turning regime, the angular speeds for each motor are different and expressed as

$$
\begin{aligned}
& \omega_{r 1}=\frac{2 v}{\left[1+\frac{R+\frac{W}{2}}{R-\frac{W}{2}}\right] R_{w}} \\
& \omega_{r 2}=\frac{2 v}{\left[1+\frac{R-\frac{W}{2}}{R+\frac{W}{2}}\right] R_{w}}
\end{aligned}
$$

where $R_{w}, R$, and $W$ are the wheel radius, turn curve radius, and axle length, respectively. Note that, from (13), the angular speed of induction motor 2 will be larger than the angular speed of induction motor 1 .

\section{B. Speed Control of Motor Drive 1}

A PI controller to maintain constant speed generates the torque command for induction motor 1 , as follows:

$$
i_{q 1}^{e *}=k_{p 1}\left(\omega_{r 1}^{*}-\omega_{r 1}\right)+\frac{k_{i 1}}{p}\left(\omega_{r 1}^{*}-\omega_{r 1}\right) .
$$

A constraint in the operation of the drive is that both motors must operate at the same frequency in order to minimize the ac current in the dc-link capacitors. Therefore, the required amount of flux $\Delta i_{d}^{e *}$ is determined by

$$
\Delta i_{d}^{e *}=k_{p f}\left(\omega_{e 1}-\omega_{e 2}\right)+\frac{k_{i f}}{p}\left(\omega_{e 1}-\omega_{e 2}\right) .
$$

Then, the differential flux is added to the nominal flux of induction motor 1 . The flux expression for motor 1 becomes

$$
i_{d 1}^{*}=\Delta i_{d}^{e *}+I_{d \text { nom }}
$$

where $\omega_{e 1}$ and $\omega_{e 2}$ are the frequencies of induction motors.

\section{Speed Control of Motor Drive 2}

The speed control for induction motor 2 involves the generation of the torque command to maintain constant velocity. Its expression in the synchronous reference frame is

$$
i_{q 2}^{e *}=-k_{p 2}\left(\omega_{r 2}^{*}-\omega_{r 2}\right)-\frac{k_{i 2}}{p}\left(\omega_{r 2}^{*}-\omega_{r 2}\right) .
$$

The flux command $i_{q 2}^{e *}$ is maintained constant at its nominal value, $64 \mathrm{~A}$. Both the flux and torque commands must be applied with negative signs. This will accomplish an out-of-phase angle of $180^{\circ}$ between the respective stator currents of both inverters. The strategy of eliminating the ac current through the dc-link capacitors is incorporated within the controls of induction motor 2, as seen in Fig. 6.

\section{Simulation RESUlTS}

The proposed drive system has been simulated assuming two identical two-phase induction motors operating at the same fundamental frequency. In all simulations except the slippage condition, the induction motors operate under similar loads. The focus of this study is the analysis of the behavior of the dc-link circulating current through the capacitors as the vehicle performs basic maneuvers. Therefore, for simplicity, the necessary torque to accelerate the vehicle and the torque to overcome the road load are modeled by a step torque. Three basic driving situations are simulated: straight line, turning, and wheel slippage. Primarily, the proposed drive system is simulated without control. Then control is applied to minimize the dc-link capacitor currents. 

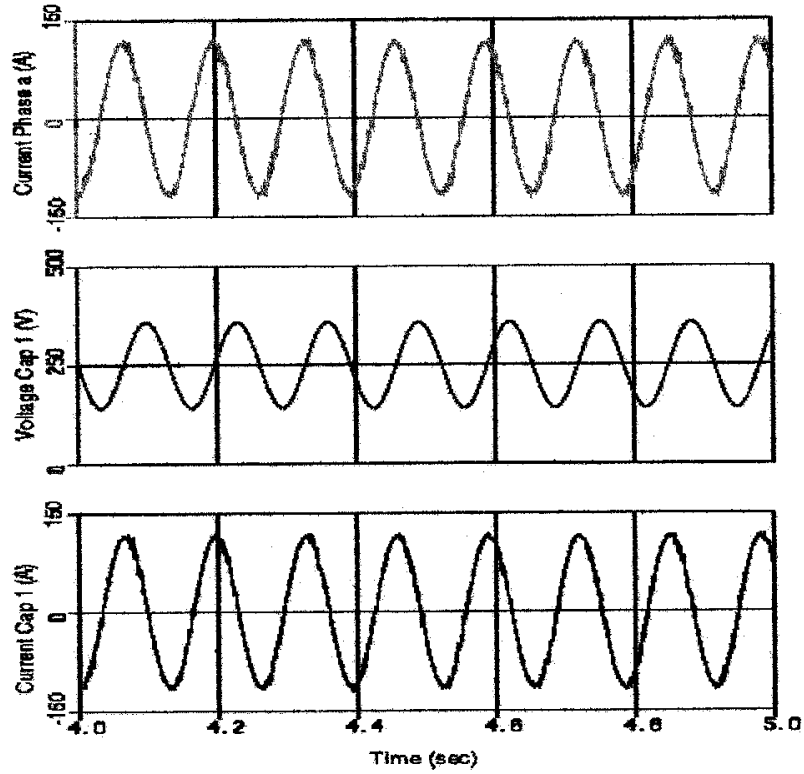

Fig. 7. Operation of the proposed drive system without control.

\section{A. Operation of the Proposed Drive Without Capacitor Current Control}

Fig. 7 shows the current and voltage through dc-link capacitor 1 when the system is operating without any control. The circulation of single-phase currents is clearly seen. This current rises as high as the current of phase $a$ (114 Apeak). In addition, due to this large capacitor current, large voltage oscillations can be seen through capacitor 1 (60 Vpeak). The same effect is produced in capacitor 2 . Without utilizing any control method to reduce the voltage and current variations, the size of the dc-link capacitors would increase. Due to the increase in loss and larger capacitors, this would have a direct impact in the weight and cost of the drive. Therefore, the single-phase current flow in the dc link must be eliminated or minimized for a practical application of the drive.

\section{B. Straight-Line Regime}

During straight-line driving operation, each inductor motor operates with identical speeds as given by (12). Fig. 8 illustrates the current through capacitor 1 . The simulation is carried out with a load of $82 \mathrm{~N} \cdot \mathrm{m}$ on each induction motor and a total vehicle velocity of $10 \mathrm{mi} / \mathrm{h}$. It can be seen that the current and voltage variations of the capacitor have been fully eliminated. According to (1), to eliminate the currents through the dc capacitors, $i_{n 1}$ and $i_{n 2}$ must total to zero. In addition, these currents must have similar magnitudes. Fig. 9 exhibits the neutral currents of the induction motors. It can be seen that the current $i_{n 1}$ increases its phase until it becomes $180^{\circ}$ out of phase with respect to the $i_{n 2}$ current. This rotation is actively accomplished by feeding the angle given by (10) into the general block diagram of Fig. 6. Because an electric vehicle will perform primarily in the straight-line regime, in which there is complete elimination of the ac current through the dc-link capacitors, the proposed drive system is attractive for electric vehicle applications.
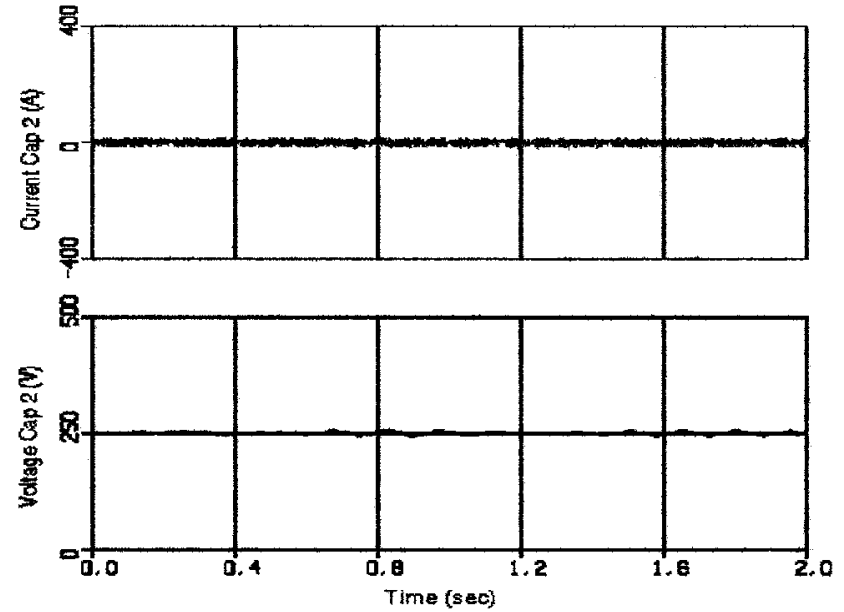

Fig. 8. Straight-line regime. DC-link capacitor voltage and current with $82 \mathrm{~N} \cdot \mathrm{m}$ in each motor.

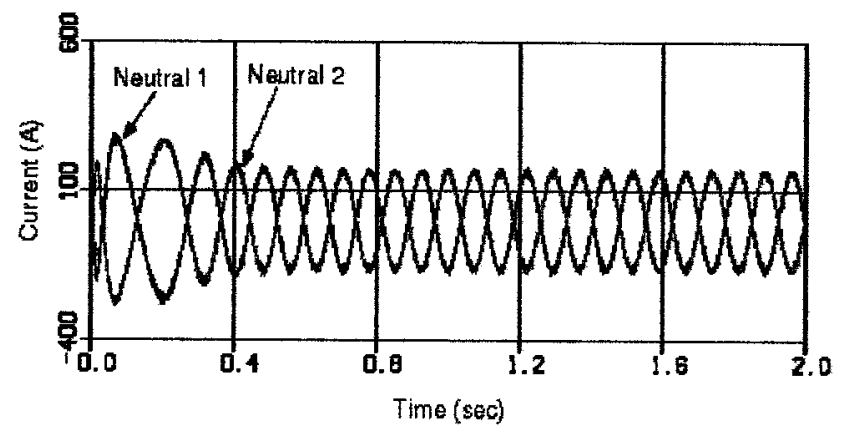

Fig. 9. Straight-line regime. Motor neutral currents $180^{\circ}$ out of phase.
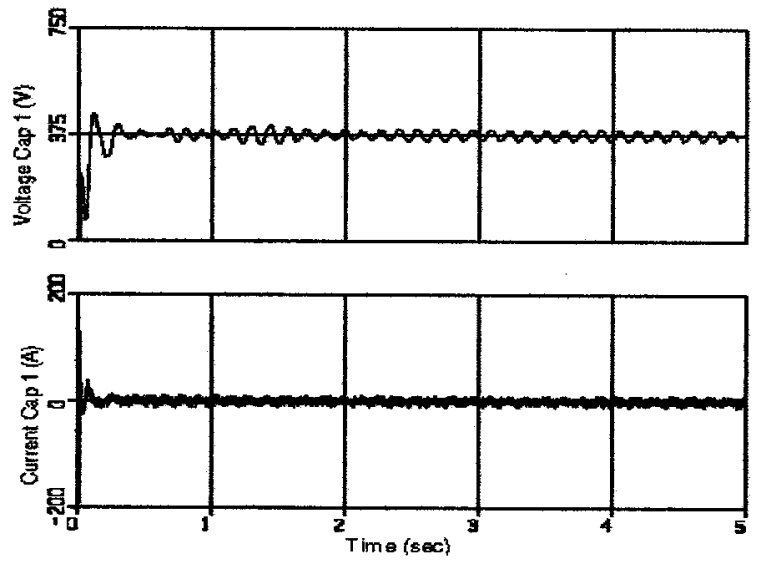

Fig. 10. Capacitor voltage and current of the proposed drive system under different speeds and same load torque (e.g., $27 \mathrm{~N} \cdot \mathrm{m}$ ).

\section{Turning Regime}

It is clear that the speeds of the motors are different for the turning condition. Given the total speed of the vehicle, the angular velocities of the motors are determined by (13) and (14). The proposed drive is capable of operating at different speeds and eliminating the single-phase current flow, as shown in Fig. 10. For this case, each induction motor operates with the same load torque (rated torque), and due to the restriction of equal frequency, motors must operate with different slip speed. The turning regime simulations demonstrate that when 


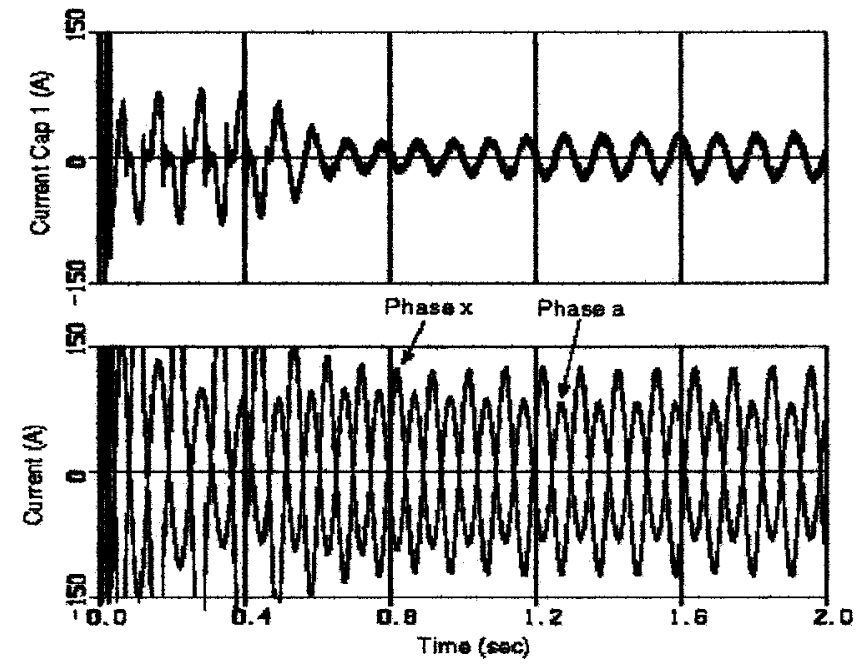

Fig. 11. Capacitor current and phases $x$ and $a$ currents during wheel slippage (simulation).

both motor drives are operated approximately with the same current level, the problem of single-phase circulating current through the dc link and voltage fluctuations can still be eliminated. It was found that aside from the difference in phase, the corresponding neutral currents remain nearly the same for this operation condition. This represents a reduction of approximately $91 \%$ of the current through the capacitors.

\section{Wheel Slippage}

One special operational condition for the drive is when one of the wheels has full traction and the other has lost almost all traction capability. This operational condition, though a rare driving situation, is important to analyze in order to determine the limitations of the drive. The simulation of wheel slippage is accomplished by applying $30 \mathrm{~N} \cdot \mathrm{m}$ on motor 1 and $82 \mathrm{~N} \cdot \mathrm{m}$ on motor 2. During the slippage condition, it is assumed that the vehicle is turning with a curve radius of $4.8 \mathrm{~m}$ at a constant speed of $10 \mathrm{mi} / \mathrm{h}$. Fig. 11 illustrates the capacitor current and voltage during the slippage operation. The currents of phase $x$ and phase $a$ are also shown. Due to the different load torque, it was found that the current in phase $x$ becomes 30 A larger than the current of phase $a$ for this load. As a result, the difference between currents will flow through the dc link, which represents approximately $25 \%$ of the current of one phase. Thus, the voltage oscillations are approximately $50 \%$ of the actual value without control. Although the elimination of the circulating current through the dc capacitor is not complete, $75 \%$ of the current can still be eliminated. This driving situation also would be a worst case scenario for the operation of the proposed drive system.

\section{EXPERIMENTAL RESULTS}

The reduced-switch concept has also been implemented in hardware. Two identical 3-hp 230-V four-pole induction machines were used, connected as in Fig. 1. Experimental traces of the three currents of one of the two induction machines connected as proposed are shown in Fig. 12. The slight distortion

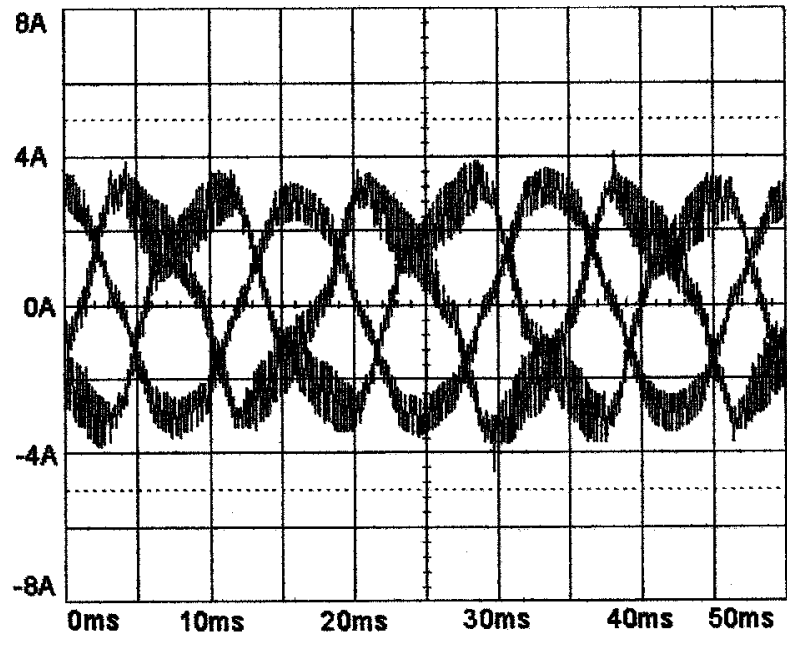

Fig. 12. Three phase currents of one of the two 3-hp induction machines.

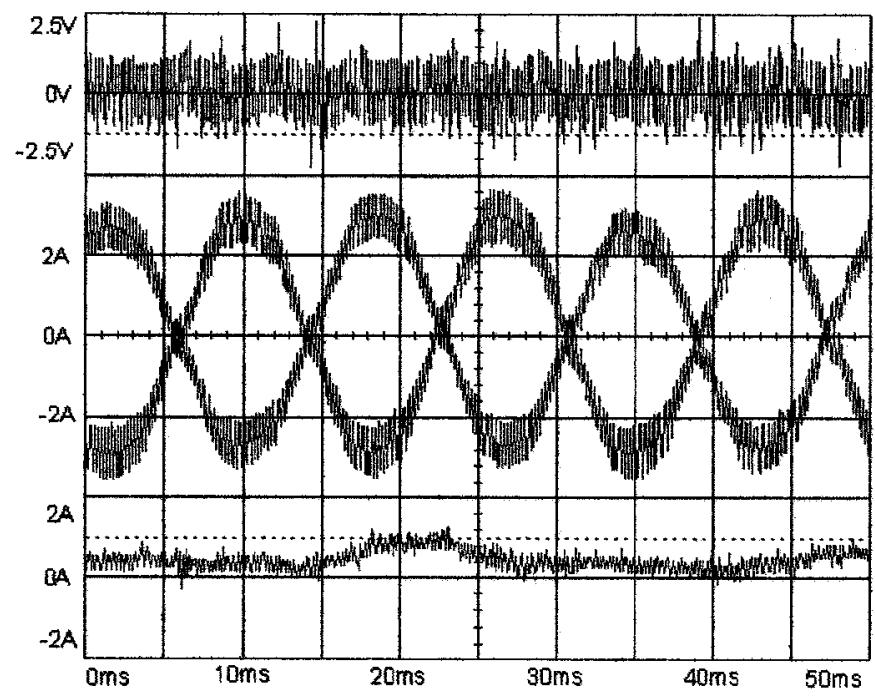

Fig. 13. Experimental results for two induction motors connected as in Fig. and operating at no load. Top trace: dc-link voltage ripple; middle traces: two phase currents of the two motors which are connected to the dc voltage link neutral,; bottom trace: sum of the two currents (ac current in the dc-link capacitor).

which occurs result from the fact that the current regulation was not employed.

Fig. 13 shows traces of the current of the motor phases which are connected to the capacitor midpoint. When the motor is unloaded, each motor operates at zero slip. Hence, the identical $\mathrm{V} / \mathrm{Hz}$ can be applied and the two motor phase currents connected to the dc-link midpoint remain equal and opposite.

In Fig. 14, the same traces are shown for the case where loads of the two machines are different. It can be noted that the resulting unbalanced currents in the phase currents of the two motors result in a large ripple current in the link capacitors and a consequent dc voltage link ripple. In Fig. 15, the same load condition is shown, but in this case with different $\mathrm{V} / \mathrm{Hz}$ on the two motors adjusted so that while the rotor speeds differ, the stator frequencies are the same. In this case, the link capacitor current and ripple voltage are greatly reduced. 


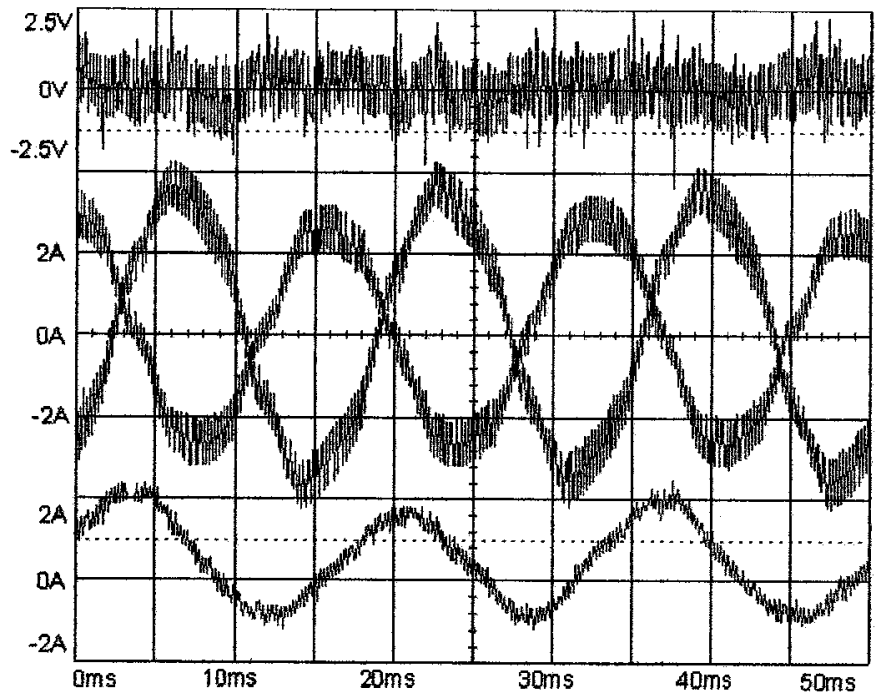

Fig. 14. Experimental results for two induction motors connected as in Fig. 1 and operating at different loads with identical applied V/Hz. Top trace: dc-link voltage ripple; middle traces: two phase currents of the two motors which are connected to the dc voltage link neutral; bottom trace: sum of the two currents (ac current in the dc-link capacitor).

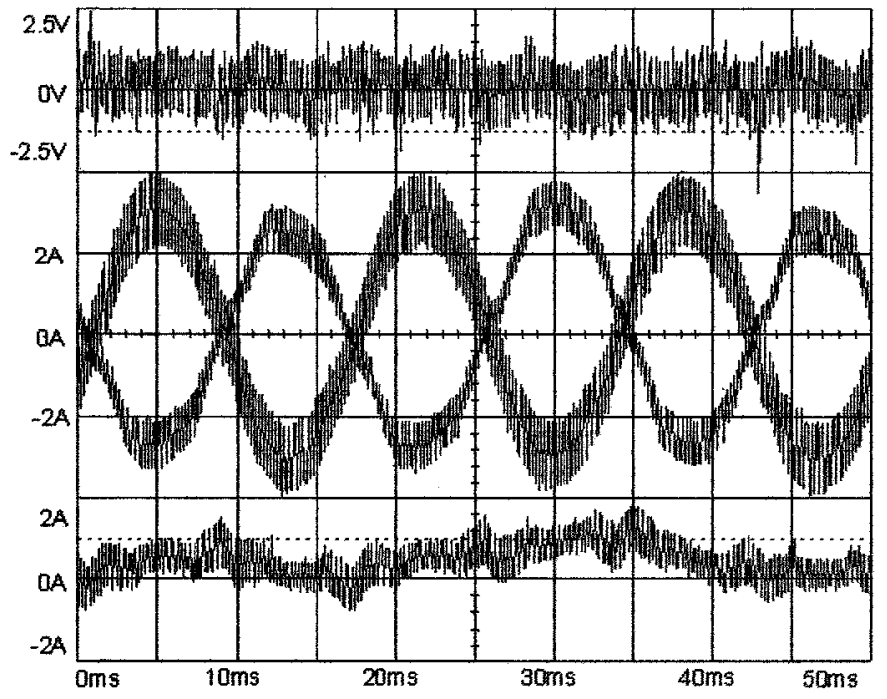

Fig. 15. Experimental results for two induction motors connected as in Fig. 1 and operating under different loads with $\mathrm{V} / \mathrm{Hz}$ adjusted to minimize link current ripple. Top trace: dc-ink voltage ripple; middle traces: two phase currents of the two motors which are connected to the dc voltage link neutral; bottom trace: sum of the two currents (ac current in the dc-link capacitor).

\section{Multimotor DRIVE APPLICATION}

In addition to traction vehicle application, the proposed drive can be utilized in industrial automation where multimachines are required to work at the same electric frequency and different speeds to control a process. Fig. 16 shows a multidrive with four identical two-phase motor drives sharing the same dc-link capacitors. The motor neutrals are connected to the center point of the capacitors. In normal conditions, this multidrive would operate with 24 switches. By using the proposed four-switch topology, only 16 switches are necessary. The multi-inverter will also exhibit the same advantages of the dual drive analyzed before: the same voltage gain and switch utilization ratio as the conventional six-switch structure, minimization of the ac cur-

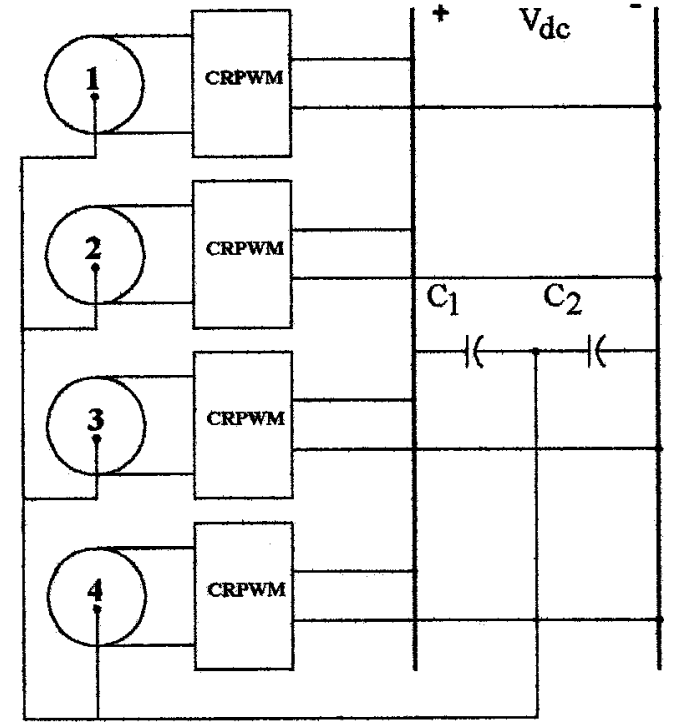

Fig. 16. Multimotor drive configuration.

rent through the dc-link capacitors, a reduced switch count, and a sharing of dc-link capacitors.

\section{CONCLUSIONS}

A dual motor drive system based on multiple two-phase PWM inverters has been proposed. The system is capable of eliminating the single-phase circulation current through the dc-link capacitors by controlling the phase angle of the commanded currents to each inverter. The elimination of the circulating current through the capacitors reduces the overall losses, eliminates dc voltage variations and has relevant impact in reducing the cost and weight of the drive. The selection of two-phase induction motors for this drive solves the reduced voltage gain problem common in four-switch topologies utilizing three-phase motors. This allows the dual four-switch inverter to have the same switch utilization as the conventional dual six-switch inverter. A multidrive application for industrial automation has been proposed and a control model for vehicle traction application has been developed and simulated, demonstrating that the proposed drive system is a suitable alternative to conventional six-switch inverter drives.

\section{APPENDIX \\ MACHINE PARAMETERS}

$20 \mathrm{hp}, 2 \phi, 127 \mathrm{~V}$, four poles

$30 \mathrm{hp}, 3 \phi, 220 \mathrm{~V}$, four poles

$L_{m}=0.007 \mathrm{H}, L_{r}=0.0072 \mathrm{H}$

$L_{s}=0.0072 \mathrm{H}$

$r_{s}=0.050 \Omega, r_{r}=0.081 \Omega$.

\section{REFERENCES}

[1] J. F. Eastham, A. R. Daniels, and R. T. Lipcynski, "A novel power inverter configuration," in Conf. Rec. IEEE-IAS Annu. Meeting, 1980, pp. $748-751$.

[2] H. W. Van Der Broeck and J. D. Van Wyk, "A comparative investigation of a three-phase induction machine with a component minimized voltage-fed inverter under different control options," IEEE Trans. Ind. Applicat., vol. IA-20, pp. 309-320, Mar./Apr. 1984. 
[3] H. W. Van Der Broeck and H. C. Skudelny, "Analytical analysis of the harmonic effects of a PWM ac drive," IEEE Trans. Power Electron., vol. 3, pp. 216-233, Apr. 1988.

[4] G. T. Kim and T. A. Lipo, "VSI-PWM rectifier/inverter system with a reduced switch count," IEEE Trans. Ind. Applicat., vol. 32, pp. 1331-1337, Nov./Dec. 1996.

[5] F. Blaabjerg, S. Freysson, H.-H. Hansen, and S. Hansen, "A new optimized space vector modulation strategy for a component minimized voltage source inverter," in Proc. IEEE APEC'95, vol. 2, 1995, pp. $577-585$.

[6] F. Blaabjerg, D. Neacsu, and J. K. Pedersen, "Adaptive SVM to compensate dc-link voltage ripple for component minimized voltage source inverter," in Proc. IEEE PESC'97, 1997, pp. 580-589.

[7] A. Bouscayrol, M. Pietrzak-David, and B. de Fornel, "Comparative studies of inverter structures for a mobile robot asynchronous motorization," in Proc. IEEE Int. Symp. Industrial Electronics, 1996, pp. $447-452$.

[8] G. T. Kim and T. A. Lipo, "DC link voltage control of reduced switch VSI-PWM rectifier/inverter system," in Proc. IEEE IECON'97, vol. 2, 1997, pp. 833-838

[9] D. W. Novotny and T. A. Lipo, Vector Control and Dynamics of AC Drives. New York: Oxford Book, 1996

[10] T. A. Lipo, "Analysis of a single-stator double-rotor ac machine," M.S.E.E. thesis, Dept. Elect. Eng., Marquette University, Milwaukee, WI, 1964.

[11] N. Mohan, T. M. Undeland, and W. P. Robbins, Power Electronics: Converters, Applications, and Design, 2nd ed. New York: Wiley, 1995.

Enrique Ledezma was born in Mazatlan, Mexico. He received M.S. degrees in electrical engineering from ITESM-Monterrey, Monterrey, Mexico, and the University of Wisconsin, Madison, in 1987 and 2000, respectively. He is currently working toward the Ph.D. degree at the University of Massachusetts.

Since 1988, he has been with ITESM, Mexico City, Mexico, as an Assistant Professor and Director of Engineering Programs. From 1997 to 2000, he was with the Wisconsin Electrical Machines and Power Electronics Consortium, University of Wisconsin, Madison, working on reduced-switch-count converter topologies and ac drives. His research interests include electric and hybrid vehicle applications for power electronics, control of motor drives, and power electronics.

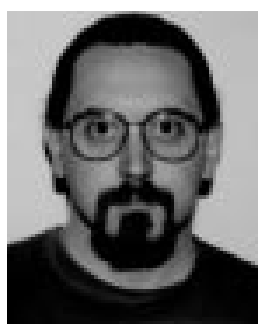

Brendan McGrath received the B.Sc. degree in applied mathematics and physics and the B.E. degree in electrical and computer systems engineering in 1997 from Monash University, Clayton, Australia, where he is currently working toward the Ph.D. degree in the Power Electronics Group.

In 1995, he was an Intern with CSIRO and the Australia Telescope National Facility and, in 1996, he was an Intern with PowerNet Victoria. He was a Research Assistant in the Power Electronics Group, Monash University, in 1997 and, during the summer of 2000, he was an Intern with the Wisconsin Electrical Machines and Power Electronics Consortium, University of Wisconsin, Madison, where he worked on reduced-switch-count motor drives. His research interests include modulation theory, multilevel converters, and fundamental control principles for power electronic converters.

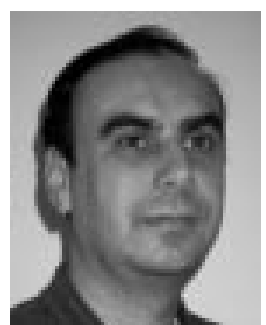

Alfredo Muñoz (M'87) was born in Valparaiso, Chile. He received the B.S. degree from the Technical University Santa Maria, Valparaiso, Chile, and the M.S. and Ph.D. degrees from the University of Wisconsin, Madison, in 1981, 1995, and 1999, respectively, all in electrical engineering.

From 1981 to 1986, he was with Schlumberger Overseas. In 1987, he became a full-time Lecturer and, in 1989, an Assistant Professor in the Electrical Engineering Department, Technical University Santa Maria. He was a Fullbright Fellow from 1993 to 1995. From 1993 to 1999 , he was a Research Assistant at the University of Wisconsin, Madison. He then joined the Scientific Research Laboratory, Ford Motor Company, Dearborn, MI. He is currently an Independent Consultant in Valparaiso, Chile, conducting research on a wide variety of ac drives, including wide-speed-range drives and high-torque-density machines. He has authored several published papers on variable-frequency drives and power electronics.

Dr. Muñoz was the recipient of the Third Prize Paper Award from the Electric Machines Committee at the 1998 IEEE Industry Applications Society Annual Meeting.

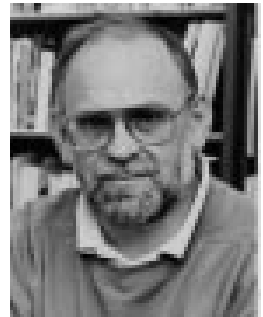

Thomas A. Lipo (M'64-SM'71-F'87) is a native of Milwaukee, WI. From 1969 to 1979, he was an Electrical Engineer in the Power Electronics Laboratory, Corporate Research and Development, General Electric Company, Schenectady, NY. He became a Professor of electrical engineering at Purdue University, West Lafayette, IN, in 1979 and, in 1981, he joined the University of Wisconsin, Madison, in the same capacity, where he is presently the W. W. Grainger Professor for power electronics and electrical machines.

Dr. Lipo has received the Outstanding Achievment Award from the IEEE Industry Applications Society, the William E. Newell Award from the IEEE Power Electronics Society, and the 1995 Nicola Tesla IEEE Field Award from the IEEE Power Engineering Societyfor his work. Over the past 30 years, he has served the IEEE in numerous capacities, including President of the IEEE Industry Applications Society. 